\title{
View from the bottom
}

\author{
(Name and address supplied)
}

Last year I was unfortunate enough to suffer a major depressive episode which required in-patient care and extensive physical treatment. I have now progressed far enough from the experience to be able to look at it more objectively, and to think about the implications it will have for my own practice of psychiatry in the future. I hope that what I have observed, reflected upon and learnt will make me a better psychiatrist, more in touch with the needs and fears of my patients, and that my view of ward dynamics "from the other side" will give me more insight into why things happen as they do. The thoughts that follow are offered not as a critique of my care, which was excellent and for which I am very grateful, but merely as a view of the practice of psychiatry from an alternative standpoint. Hopefully they may encapsulate some of the difficulties faced by the depressed in-patient, although of course they cannot presume to speak for those suffering from other forms of psychiatric illness.

\section{The patient}

Coming into hospital can be viewed by the patient as failure on any number of levels - failure of the doctors to get him better, failure of the medication, failure of external support systems, but above all failure of himself to respond to the assistance which has already been offered and which seems to be more than enough to aid recovery in others. As an in-patient, a sense of failure is likely to dog the patient who has perhaps always had unrealistic goals and expectations, and the medical and nursing staff can help build self-esteem by sensitively, and probably repeatedly, discussing realistic targets and progress while admitting that these may need to be modified in either direction according to the patient's clinical state. Becoming an in-patient also exemplifies the patient's perceived lack of control over his own life, as suddenly nothing in life-family, work, relationships - is quite as it seemed, and nothing can be relied upon with certainty any more. At these times there seems to be nothing to hold on to, for the only thing that seems to be immutable is that the future will bring more pain and confusion.

Another difficulty which may hinder the therapeutic efforts of staff is the patient's indecisiveness, vacillation and ambivalence. The ability to make rational judgements may be lost, as well as the innate ability to appreciate the relative importance of different decisions. Whatever the mental mechanism underlying this, it can be as incapacitating to the patient as it is irritating to others. These skills may also be gradually eroded by the process of institutionalisation, which is probably inevitable to some extent in all but the briefest in-patient stay. Institutionalisation is enhanced by the patient's withdrawal and apathy which prompt the staff to take increasing responsibility for different aspects of his functioning within the ward milieu. It is sometimes difficult for staff and visitors to appreciate the importance of predictable events during the day in imposing some semblance of order on what may be internal chaos, and to understand the apparent obsessionality and intolerance of minor changes in ward routine or in the patient's own programme. Once again the carers must perform a difficult balancing act, to encourage the patient to keep things in proportion while striving not to introduce unnecessary changes of plan which may cause distress, such as not keeping an appointment with the patient, altering medication without discussion, etc.

The expectations that the patient is expected to fulfill gradually become more apparent to him with clinical improvement to a stage which once again allows him to take cognisance of things other than his internal world. The desire to please, to talk about the right things in the ward round, to feel the treatment is helping, and above all not to be any trouble to anyone, is probably likely to be felt more intensely by a psychiatrist patient than anyone else. It is perhaps understandable that in the later stages of recovery this may be accompanied by a lingering resentment that one is in fact the same as everyone else and responds in a standard way to standard treatment!

Friends and relatives experience many of the same difficulties in dealing with the depressed in-patient as the staff. Feelings of guilt and worthlessness, together with indecisiveness and ambivalence, mean that he feels extremely guilty when people phone or visit, and rejected when they do not. This may need to be explained to visitors unfamiliar with mental illness, who may otherwise feel useless or undervalued themselves.

My in-patient stay served to reaffirm that stigmatisation of mental illness was alive and kicking. Even medical (though not psychiatrist) friends referred to the "loony bin" and asked me about the "other 
inmates" and when I was going to be "released". What, in retrospect, seems more surprising is the way that I applied my own stigma, denying myself potential support from friends and colleagues by refusing to let them know where I was. No doubt I am now somewhat oversensitive to the way in which patients are referred to, but the first time that I went onto a ward as a doctor again I found that some would-be joker had removed the notice saying "Now wash your hands please" from the staff toilet and stuck it on the patients' notes trolley.

\section{The treatment}

It seems that there is a price to pay in terms of side effects for the efficacy of any psychotropic medication, but I was surprised to find how bad these unwanted effects could get. It may be that the doctor can offer only symptomatic relief or none at all, but sympathetic enquiry itself can help the patient by legitimising his complaints. It is easy for a depressed patient to become preoccupied with problems such as thirst, tremor and clumsiness, constipation or urinary retention, which may be bad enough to cloud the picture of an improving mental state. The staff should also bear in mind the effect that the treatment, as well as the illness, may have on cognitive function, as this may be an added distress for a patient who cannot appreciate what is happening or the fact that the impairment is temporary.

Despite having worked on a unit where ECT was often used, I was totally unprepared for the magnitude of the memory loss that I suffered, although I recognise that many patients experience only a transient short-term deficit, or none at all. I assume that the reason I did not become distressed about this until after the course was completed was that it was only with improvement in mood and interest that I began to try and think about things other than day to day life on the ward. I could not remember what my car or things in my house looked like, or what my job was, and when the time came for weekend leave I was unable to find my way home. Although my memory for faces remained intact, I could not remember the names of my friends, and I could not write Christmas cards for several weeks until the entries in my address book began to look familiar once again. My spelling was uncharacteristically poor, and the mistakes often involved substituting another word with the same sound but a different meaning. Regaining my memory was not a passive phenomenon, either, but involved a lot of persistence on my part and patient reality orientation by friends and relatives.

\section{Other patients}

My in-patient stay made me realise that in my clinical practice I had been ignoring an important variable - the influence of patients on one another. Sometimes this was direct, with the formation of same-sex and opposite-sex pair bonds, and sometimes indirect, with one patient influencing the relationship another patient had with medical and nursing staff. Understanding these links was sometimes the key to explaining sudden changes in mood or acting out behaviour. Although undoubtedly relationships between patients could be mutually supportive, they could at times go some way to explaining a perceived lack of improvement. Some patients obviously had a vested interest in prolonging their stay, and it was no surprise to find that they exaggerated their symptoms or actually lied about them. Non-compliance with medication was another area in which the actions of patients were influenced by others, and sometimes it was done with an ostentatiousness that begged discovery.

\section{The staff and the ward}

The ward operated a key worker system which was appreciated by the patients. I preferred to see both my key worker and the doctor less often, but for a longer time, thus avoiding the simplistic "How are you today?" approach, which can be intensely irritating to the patient, as it invites an equally meaningless reply and signals that the questioner wants a quick, global answer so that he can move on. "How are you sleeping?" can be equally frustrating when asked as part of a flying visit. In my future clinical practice I will place more emphasis on how a depressed patient describes his own sleep pattern, as it seems that if the night nurse does not shine a torch in the patient's face she cannot tell whether he is asleep or awake, and if she does then he is woken anyway! The clinical experience of the nurses was obvious, and the student nurses' attempts to make conversation could be gauche, and at times patronising. This was particularly evident on ECT days, and I knew from my clinical experience that it was often only the least experienced student who could be spared from a busy ward to go to the ECT suite. It must be a difficult task for a novice to reorientate the confused patient after the treatment without talking down to him, and to be helpful without displaying dismay at the fact that he cannot remember anything about it. On the ward, the student nurses sometimes seemed noticeably wary and ill at ease with patients, preferring to spend time with the elderly ones where they could concentrate on physical problems.

Stigma or no, I preferred to regard the ward as a ward, not a community, and myself as a patient, not a resident or client. It remained difficult to see how such a disparate array of people, some held against their will, with only some sort of psychiatric diagnosis in common, could form the sort of links a community needs. Certainly there was no notion of 
mutual responsibility, as the squalor of the patients' kitchen and the thefts from the laundry room served to demonstrate. From the staff side, there was a fine line to be drawn between encouraging patients to support themselves and letting them interfere with each other's management.

Ward atmosphere obviously changed according to the activities of its most vociferous patients, but it was at its most depressing whenever the doors were locked during the day. This measure was only used when absolutely necessary, but it always had an effect on morale and increased the sense of stigmatisation already felt by many. Ward routine was very important for many patients, particularly those who had improved sufficiently to take an interest in the programme offered, but at the same time they could be very unflexible and intolerant of change or interruption. An important aspect of ward policy in encouraging reintegration into normal living when the time came was therefore the flexible and tolerant approach to visiting hours and leave arrangements.

\section{Acknowledgements}

I would like to thank the medical and nursing staff who helped me through what could have been a nightmare. My thanks are due particularly to Jo, Tony and David for their care and help, and to Charlie, Ivana, Andrew, Jo, Richard, Lesley, Helen and Shelagh for their unstinting support.

\title{
Multi-centred day units in a psychiatric rehabilitation service
}

\author{
N. Rothwell, Principal Clinical Psychologist; A. A. McKeChNIE, Consultant \\ Psychiatrist*; and D. LoRIMER, Research Assistant, Bangour Village Hospital, \\ Broxburn, West Lothian EH52 6LW \\ *now HM Medical Commissioner, Mental Welfare Commission for Scotland, \\ 25 Drumsheugh Gardens, Edinburgh EH3 7RB
}

Psychiatric day care has expanded considerably over the past 20 years. Day hospitals may serve as alternatives to short-stay in-patient units or speed discharge from them. Day services are also necessary to ensure appropriate support for patients with chronic disability, especially chronic functional psychosis, if they are to remain in a community setting (these are often called day hospitals to ensure NHS support). The present paper focuses on this latter group and describes the characteristics of day attenders in a service that has developed a multi-facility approach to community support.

Bangour Village Hospital provides a comprehensive service to a population of approximately 140,000 . It has a day hospital specifically identified as a rehabilitation and long-term support facility which provides 40 places on a 5 -day week basis with major emphasis on work placement or participation in an occupational therapy programme. Associated with the day hospital are two community clubs run on a sessional basis by day hospital staff. One unit, the Whitburn ' $81 \mathrm{Club}$, is based in a community centre and provides facilities within this with support principally from NHS staff. The second facility is based in a community school in Livingston New Town and activities are conducted there on a sessional basis using NHS and community education staff. A community school provides vocational and non-vocational educational facilities for children and adults. It is open six days a week for most of the year for up to 14 hours a day.

Depot neuroleptic clinics are also held in various locations within the catchment area. 